\title{
Stage IV Renal Pelvis Cancer AJCC v7
}

National Cancer Institute

\section{Source}

National Cancer Institute. Stage IV Renal Pelvis Cancer A/CC v7. NCI Thesaurus. Code C6147.

Stage IV includes: (T4, N0, M0); (Any T, N1, M0); (Any T, N2, M0); (Any T, N3, M0); (Any $\mathrm{T}$, Any N, M1). T4: Tumor invades adjacent organs, or through the kidney into perinephric fat. N0: No regional lymph node metastasis. N1: Metastasis in a single lymph node, $2 \mathrm{~cm}$ or less in greatest dimension. N2: Metastasis in a single lymph node, more than $2 \mathrm{~cm}$ but not more than $5 \mathrm{~cm}$ in greatest dimension; or multiple lymph nodes, none more than 5 $\mathrm{cm}$ in greatest dimension. N3: Metastasis in a lymph node, more than $5 \mathrm{~cm}$ in greatest dimension. M0: No distant metastasis. M1: Distant metastasis. (AJCC 7th ed.) 